\title{
Pristine submucosal visibility using Texture and Color Enhancement Imaging during saline-immersion rectal endoscopic submucosal dissection
}

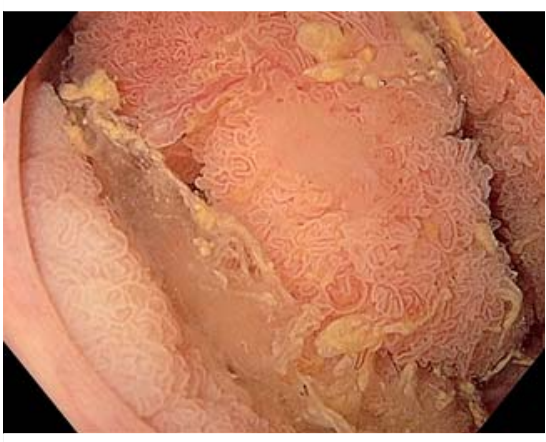

- Fig. 1 High-definition white-light examination of a large villous Paris O-Is + Ila rectosigmoid polyp.

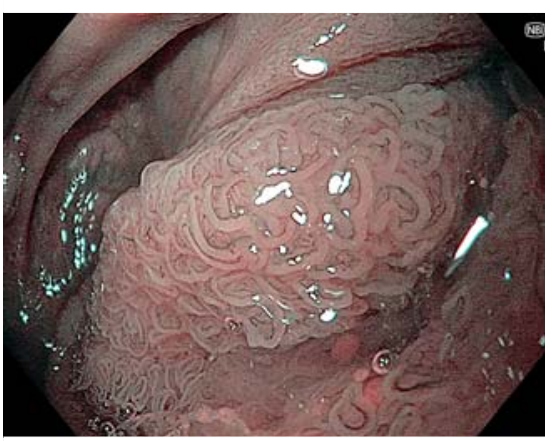

- Fig. 2 Narrow-band imaging examination with near focus of the villous part of the lesion, which is classified NICE II, JNET-2A with benign features.

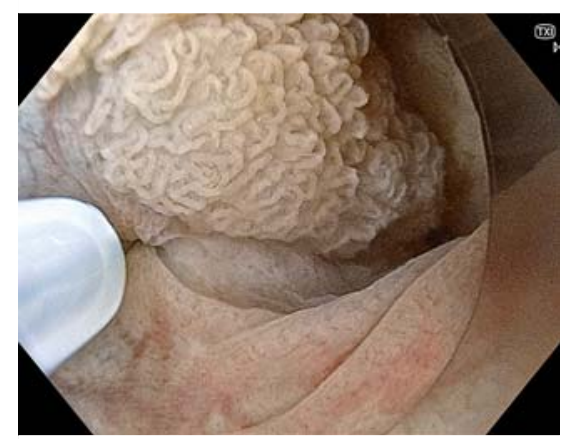

Fig. 3 Texture and Color Enhancement Imaging (TXI) mode under saline immersion conditions with clear identification of the limits of the lesion. Lifting is obtained with glycerol injection into the submucosa in these conditions.

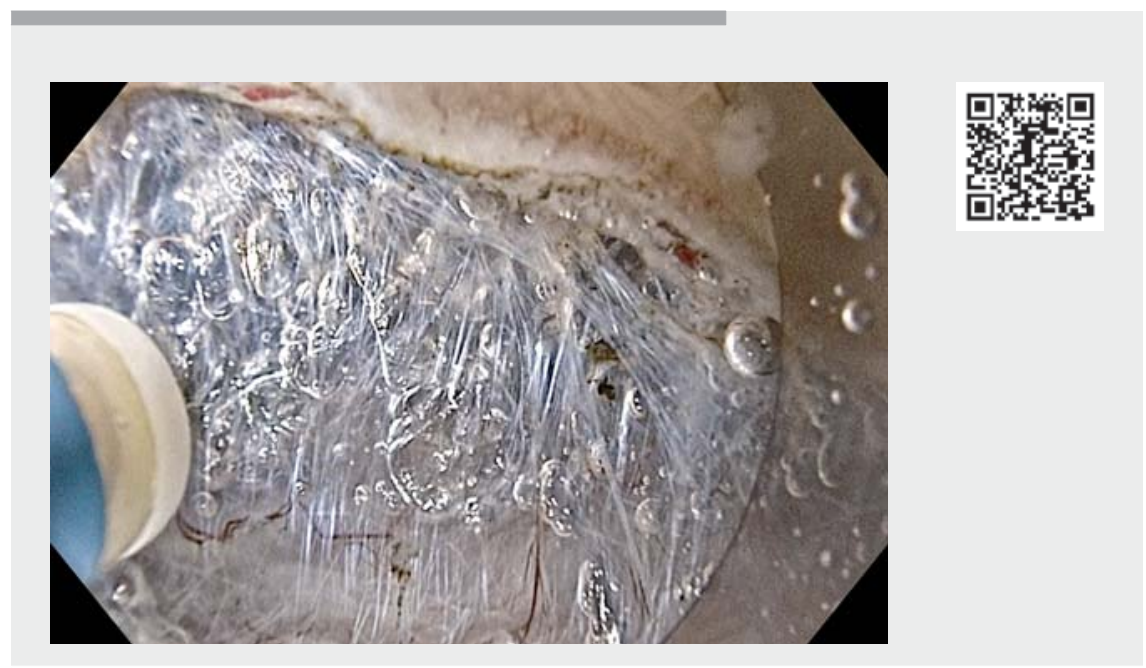

$\checkmark$ Video 1 Use of Texture and Color Enhancement Imaging (TXI) combined with near focus during the dissection step of saline-immersion colorectal endoscopic submucosal dissection offers pristine submucosal visibility: a case of a large traditional serrated adenoma.

Endoscopic submucosal dissection (ESD) is spreading worldwide to remove large protruded adenoma in the colorectum with the aim to obtain adequate pathological examination and virtual recurrence rate [1]. Up to now, no virtual enhancement tool has been described to facilitate submucosal visibility during submucosal space endoscopy.

The new Texture and Color Enhancement Imaging (TXI; Olympus, Tokyo, Japan) that enhances the texture and corrects the color tone and brightness was initially designed to better detect and assess margins of early neoplasia [2]. We report here the synergistic added value of TXI and near-focus mode when used during saline-immersion ESD by improving submucosal space visibility ( $\bullet$ Video 1 ).

A 39-year-old man was diagnosed with a granular laterally spreading tumor (LST), with a large villous nodule (Paris O-Is-IIa) of $50 \mathrm{~mm}$ on $30 \%$ of the circumference, located at the rectosigmoid junction ( Fig.1). Magnifying narrow-band imaging (NBI) revealed a NICE II, JNET 2A lesion ( $\bullet$ Fig.2), and biopsies revealed low-grade dysplasia.

We conducted an en bloc resection by ESD using a GIF-HQ190 (Olympus) gastroscope in TXI mode associated with near focus. Being on the gravity side, the whole procedure was performed under saline immersion conditions ( $\triangleright$ Fig. $\mathbf{3}$ ). After proximal lifting using glycerol solution with blue dye, a mucosal incision was made with the DualKnife J. The submucosal space was opened with a scope waterjet, allowing progressive dissection under $50 \%$ of the lesion in the retroflex position. Visibility in the submucosal space was impressive with respect to the brightness and sharpness of the submucosal fibers, muscular plane, and vessel recognition ( Fig.4). Thereafter, the distal side was opened and dissected to obtain a specimen of $85 \times 70 \mathrm{~mm}$ ( $\triangleright$ Fig.5). The histopathological examination of the specimen showed a traditional serrated adenoma with low grade dysplasia with free margins [3]. 


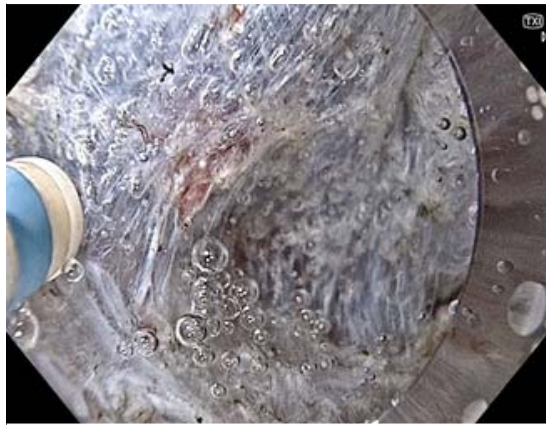

> Fig. 4 Texture and Color Enhancement Imaging (TXI) mode during the submucosal dissection step of the procedure was associated with bright and clear visibility of the submucosal fibers and location of vessels as well as the muscular plane.

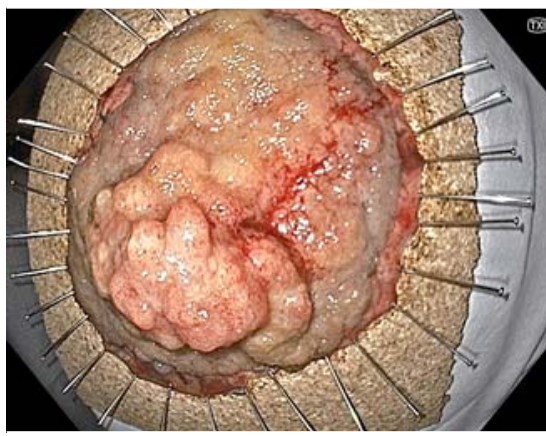

- Fig.5 Picture of the specimen resected en bloc.

This case illustrates the impressive technical step offered when combining saline immersion, near-focus and TXI mode to enhance visibility of planes during submucosal space endoscopy.

Endoscopy_UCTN_Code_CPL_1AJ_2AD

\section{Competing interests}

The authors declare that they have no conflict of interest.

\section{The authors}

\section{Arnaud Lemmers $^{1} \stackrel{\odot}{ }$, Ana-Maria Bucalau ${ }^{1}$,} Laurine Verset $^{2}$, Jacques Devière ${ }^{1}$

1 Department of Gastroenterology, Hepatopancreatology and Digestive Oncology, CUB Erasme Hospital, Université Libre de Bruxelles (ULB), Brussels, Belgium

2 Bordet Institute, Pathology Department, Brussels, Belgium

\section{Corresponding author}

\section{Arnaud Lemmers, MD, PhD}

CUB Hôpital Erasme, ULB (Université Libre de Bruxelles), Route de Lennik, 808 , 1070 Brussels, Belgium

Fax: +32-2-555-4697

arnaud.lemmers@erasme.ulb.ac.be

\section{References}

[1] Fuccio L, Hassan C, Ponchon T et al. Clinical outcomes after submucosal dissection for colorectal neoplasia: a systematic review and meta-analysis. Gastrointest Endosc 2017; 86: 74-86

[2] Shikawa T, Matsumura T, Okimoto K et al. Efficacy of Texture and Color Enhancement Imaging in visualizing gastric mucosal atrophy and gastric neoplasms. Sci Rep 2021: 11: 6910
[3] Anderson J, Srivastava A. Traditional serrated adenomas: what the endoscopist should know. Gastrointest Endosc 2019; 90: 647650

Bibliography

Endoscopy 2022; 54: E310-E311

DOI 10.1055/a-1524-1298

ISSN 0013-726X

published online 9.7.2021

(C) 2021. Thieme. All rights reserved.

Georg Thieme Verlag KG, Rüdigerstraße 14, 70469 Stuttgart, Germany

\section{ENDOSCOPY E-VIDEOS}

https://eref.thieme.de/e-videos

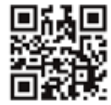

Endoscopy E-Videos is an open access online section, reporting on interesting cases and new techniques in gastroenterological endoscopy. All papers include a high quality video and all contributions are freely accessible online. Processing charges apply (currently EUR 375), discounts and wavers acc. to HINARI are available.

This section has its own submission website at https://mc.manuscriptcentral.com/e-videos 